\title{
A Motivational Framework For Understanding IS Use And Decision Performance
}

Siew H. Chan, (E-mail: Siew.Chan@wmich.edu), Western Michigan University

\begin{abstract}
Despite the considerable resources that have been devoted to the study of information systems (IS) use and decision performance, much remains unknown about variables that provide valuable insight into these two important constructs. We propose a comprehensive research framework for understanding IS use and decision performance. In particular, we focus on the significant role of the motivation factor in explaining IS use and decision performance. We develop our research framework based on a review of motivation, systems, decision performance, information processing, and auditing literatures. A new stream of research is presented based on our motivational framework.
\end{abstract}

\section{INTRODUCTION}

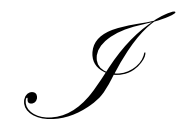

nformation systems (IS) are designed to meet a wide variety of objectives including supporting organizations' operations and providing useful information for decision-making. In particular, IS are intended to support decision-making (Keen \& Scott-Morton, 1978), increase decision quality (Kanungo, Sharma, \& Jain, 2001; Kasper 1996; Singh, 1998), enhance effectiveness and productivity (Forgionne \& Kohli, 1996), serve as a tool for analyzing and solving complex tasks (Balakrishnan \& Jacob, 1995), and attain system success (Kohli \& Devaraj, 2002). However, "(i)nformation technology adoption and use in the workplace remains a central concern of information systems research and practice" (Venkatesh \& Davis, 2000, p. 186). "Low usage of installed systems has been identified as a major factor underlying the 'productivity paradox' (Venkatesh \& Davis, 2000, p. 186), the label given to weak economic returns organizations have realized from their investments in information technology (Sichel 1997). Although potential benefits can be derived from IS use, individuals may still choose not to use the IS (Boatsman, Moeckel, \& Pei, 1997; Chenoweth, Dowling, \& St. Louis, 2003). Underutilization of decision rules (Davis \& Kottemann, 1995) and poor user acceptance of new technologies (Keil, 1995; Swanson, 1988) can impair decision performance; therefore, increased understanding is needed on factors that affect IS use. Despite the considerable resources that have been devoted to the study of IS use and decision performance, much remains unknown about variables that provide valuable insight into these two important constructs.

A considerable amount of attention has been directed at the acceptance and use of IS. The theory of reasoned action (Ajzen \& Fishbein, 1980) and the technology acceptance model (TAM) are widely used to predict and explain user acceptance and rejection of computer-based systems. The theory of reasoned action suggests that individuals use IS when they perceive benefits associated with such usage. TAM, an adaptation of the theory of reasoned action, is designed for modeling user acceptance of IS (Davis, 1989). This model is viewed as the "motivational model of technology usage" (Venkatesh \& Speier, 1999, p. 2). Prior studies have used TAM extensively to predict IS use (e.g., Adams, Nelson, \& Todd, 1992; Chau, 1996; Davis, 1989; Davis, Bagozzi, \& Warshaw, 1989, 1992; Lederer, Maupin, Sena, \& Zhuang, 2000; Teo, Lim, \& Lai, 1999). However, few studies of IS related issues have examined the motivation factor. For example, overall intrinsic motivation was assessed by asking the participants two questions: how making predictions provided them with a new way of looking at bankruptcy predictions and how the challenge of making predictions aroused their interest in those predictions (Becker, 1997). A scale was used to measure perceived enjoyment and participants were asked whether they felt that using a word processing program was enjoyable, pleasant, and fun to use (Davis, Bagozzi, \& Warshaw, 1992). Meaningfulness of a 
task was considered via expectation of the possibility that an IS would be used in the near future (Hunton \& Price, 1997). Further, affect did not have an impact on IS use (Cheung, Chang, \& Lai, 2000; Yang \& Yoo, 2003). These studies have been very informative but have often had mixed results. We believe an important psychological construct -- motivation -- can prove informative. We find that a thorough examination of the role of motivation in IS use and decision performance has not been attempted and yet the possibility of their contribution in explaining IS use and decision performance is compelling. An examination of the motivation factor not only offers insight into the mixed findings and but also helps us consider ways to encourage use of IS and obtain improved decision performance. IS use is posited to occur when the benefits (i.e., accuracy) outweigh the costs (i.e., cognitive effort) associated with usage (Todd \& Benbasat, 1996)

\section{MOTIVATIONAL FRAMEWORK}

Figure 1 shows our motivational framework for understanding IS use and decision performance. This framework is developed based on a review of the motivation, systems, decision performance, information processing, and auditing literatures.

Our research framework suggests that IS characteristics affect user perceptions of the IS which in turn affect motivation to use the IS. The characteristics of the IS include ease of use (Davis, 1989), presentation format (Amer, 1991; Hard \& Vanecek, 1991; Umanath, Scamell, \& Das, 1990), system restrictiveness (Silver, 1990), decisional guidance (Silver, 1990), feedback (Eining \& Dorr, 1991; Gibson, 1994; Stone, 1995), and interaction support (Butler, 1985; Eining, Jones, \& Loebbecke, 1997). The perceptions of the IS construct includes effectiveness (Payne, Bettman, \& Johnson, 1993), efficiency (Farivari \& Levy, 1983; Williams, 1973; Youmans, 1981), and effort (Eisenberger \& Cameron, 1996; Todd \& Benbasat, 1992, 1994). The users' ability, knowledge, and experience (Libby \& Luft, 1993) in the use of a particular IS moderate the relationship between IS characteristics and user perceptions of the IS, especially in the case of use of a similar IS.

Figure 1 also shows the factors that affect task motivation. Task motivation (Amabile, 1983, 1988) is influenced by the following five factors: user perceptions of the task, users' motivational orientation, decision environment, task characteristics, and task/user characteristics (ability, knowledge, and experience). First, the four task values driving user perceptions of the task (Eccles (Parsons), Adler, Futterman, Goff, Kaczala, Meece, \& Midgley, 1983) include interest, importance, utility, and cost. Second, the users' motivational orientation (Amabile, Hill, Hennessey, \& Tighe, 1994) provides a baseline for their initial level of motivation toward a task. Third, extrinsic incentives (Deci, 1971; Kruglanski, Friedman, \& Zeevi, 1971; Lepper, Greene, \& Nisbett, 1973), justification (Peecher, 1996), accountability (Kennedy, 1993), and time constraint (Chu \& Spires, 2001; Davis, 1994) are factors in the decision environment that affect task motivation. Fourth, task characteristics such as complexity (Bonner, 1994), difficulty (Stone \& Kadous, 1997), structure (Bonner, 1994; Simon; 1973), ambiguity (Brown \& Jones, 1998), and novelty (Hennessey \& Amabile, 1988) also have an impact on task motivation. Finally, the users' ability, knowledge, and experience (Libby \& Luft, 1993) are task/user characteristics that influence task motivation.

\section{CONSTRUCTS IN THE FRAMEWORK}

\section{IS Characteristics}

The IS characteristics include ease of use, presentation format, system restrictiveness, decisional guidance, feedback, and interaction support.

Ease Of Use

IS use is expected to occur if users perceive the IS to be easy to use and that using it enhances their performance and productivity (Igbaria, Zinatelli, Cragg, \& Cavaye, 1997). Ceteris paribus, less cognitive effort is needed to use an IS that is easy to use, operate, or interact with. The extent of ease of use of an IS is dependent on features in the IS that support the dimensions of speed, memory, effort, and comfort (Thomas, 1996). An IS is easy to use if it reduces user performance time (i.e., the IS is efficient), decreases memory load with the nature of assistance 
provided (memory), reduces mental effort with simple operations (effort), and promotes user comfort (comfort). An objective of developers is to reduce the effort that users need to expend on the task by incorporating the ease of use characteristic in the IS so that more effort can be allocated to other activities to improve decision performance. IS use may decline if increased cognitive effort is needed to use the IS because of lack of ease of use.

User characteristics such as ability, knowledge, and experience in the use of an IS affect user perception of the ease of using a similar IS. The perceived ease of use construct has been proposed and used extensively as a surrogate measure for the ease of use characteristic. Perceived ease of use is defined as the extent of a person's belief that use of an IS is relatively free of effort (Davis, 1989; Davis et al., 1989). In other words, perceived ease of use refers to a person's perception about the amount of effort necessary for using an IS and the degree of her belief that use of an IS improves her decision performance (Venkatesh, 1999). Since users are frequently requested to evaluate or assess their experience in terms of the process of their interaction with the IS, perceived ease of use is considered to be a process expectancy (Venkatesh, 1999). Favorable perceived ease of use is a significant determinant of initial acceptance of an IS and is essential for adoption and continued usage of the IS (Davis et al., 1989).

\section{Presentation Format}

Presentation of a problem can be modified based on the assumption that information is correctly processed when it is presented in a form that evokes appropriate mental procedures (Roy \& Lerch, 1996). The prospect theory (Kahneman \& Tversky, 1979) suggests that presentation (framing) of alternatives can affect the riskiness of decision outcomes. This theory suggests that the way information is presented may influence a user's judgment or decision. In addition, the cognitive fit theory (Vessey, 1991; Vessey \& Galletta, 1991) indicates that the level of complexity in a given task is reduced effectively when the problem-solving tools or techniques support the methods or processes required for doing the task. Thus, problem solving with cognitive fit results in efficiency and effectiveness gains. The presentation format used for displaying accounting information can have an impact on human judgment accuracy. Researchers have examined (1) the impact of a change in the report format for displaying accounting information on the participants' ability to detect a change in the financial status of the firm (Stock \& Watson, 1984); (2) whether the use of graphical formats would assist rather than hinder decision making (Jarvenpaa, 1989); (3) whether the type of decision task and display of multicue financial information have an impact on decision making performance and user perception about display use (Amer, 1991); and (4) whether a more effective mental representation is elicited by changing the presentation format (Roy \& Lerch, 1996). The results of these studies suggest that improved decision performance results when a fit exists between the task and the IS used to do the task.

\section{System Restrictiveness And Decisional Guidance}

Two IS attributes, system restrictiveness and decisional guidance, have been examined to show what users can and will do with the IS (Silver, 1990). System restrictiveness refers to the degree to which the IS limits the options available to the users, and decisional guidance refers to the IS assisting the users to select and use its features during the decision-making process. If a decision-making process encompasses the execution of a sequence of information processing activities to reach a decision, then both the structure and execution of the process can be restricted by the IS. The structure of the process can be restricted in two ways: limit the set of information processing activities by providing only a particular subset of all possible capabilities, and restrict the order of activities by imposing constraints on the sequence in which the permitted information processing activities can be carried out. User involvement is often essential during the execution of information processing activities after the structure of the process has been determined. The structure in the decision-making process could also be promoted with the use of a restrictive IS; in this respect, users are not overwhelmed with choices among many competing IS. In certain cases, additional structure may actually enhance IS use by making it easier for users to operate. However, lesser system restrictiveness may be preferred to enhance learning and creativity. Since IS use may be viewed to be discretionary, users may not use an IS that is too restrictive (Silver, 1988). 


\section{Feedback}

Feedback can be classified into the following three categories: outcome, task properties, and cognitive (Hirst \& Luckett, 1992). Users receive outcome feedback when they are provided with information as to whether their decisions are correct. Task properties feedback is given when users receive specific information pertaining to the optimal weighting associated with the various pieces of information. Cognitive feedback refers to information received on cue utilization; this type of feedback is associated with judgment processes (Arnold, 1997).

The literature on feedback has reported mixed findings. For example, expert systems users performed better than the no-system and questionnaire groups in terms of time and accuracy; however, the feedback treatment did not have a significant impact on performance (Eining \& Dorr, 1991). Further, all feedback groups were found to outperform the no-feedback group, task properties feedback initially resulted in higher performance, and performance improved over time in the presence of outcome feedback (Hirst \& Luckett, 1992). Feedback types, not screen layouts, had a significant effect on productivity or user satisfaction (Gibson, 1994), and the type of feedback affected the decision process or decision performance (Stone, 1995). Individuals in the outcome feedback condition made more accurate choices and had greater self-insight into their decision performance, while those in the decision-process feedback condition had greater self-insight into their decision processes (Stone, 1995). Although individuals confused their actual decision models with the task information and outcome feedback (Tuttle \& Stocks, 1997), decision performance improved when outcome feedback was present because these individuals brought meaning to the task with their accounting-domain knowledge (Tuttle \& Stocks, 1998). Thus, decision performance is affected by interaction between feedback and task property information.

\section{Interaction Support}

Interaction support is present when users are allowed a certain level of interactivity with the IS. The design of an IS has a determining effect on the degree of interaction between the IS and the user (Silver, 1990). Individuals may perceive control over the IS when some level of interaction support is provided by the IS. Perceived control over the use of the IS may have positive effects on motivation to use the IS. Indeed, motivation is enhanced by the provision of information choice (Becker, 1997). In particular, individuals using an IS that allowed user input (choice) in determining the IS contents were more motivated than those using an IS that did not allow this input (Roth, Bennett \& Woods, 1987). The effectiveness and acceptance of an IS increased when users were provided with some control over the IS (Roth et al., 1987). In an audit context, auditors were asked to use an IS to guide them in their report of past experience with an audit-related issue prior to decision-making (Butler, 1985). The IS required a certain level of interaction from the user. Compared to auditors in the no-IS condition, auditors in the IS condition were more accurate in judgment (Brown \& Eining, 1996). In a study where IS with different levels of interaction support were designed, expert system users were reported to be in more frequent agreement with the IS than the statistical model and checklist users (Eining et al., 1997). Specifically, individuals using the IS with increased interaction support placed more reliance on the IS than those using the IS with limited interaction support. Thus, the interaction support provided by the IS has a positive impact on IS use (Brown \& Eining, 1996).

In summary, several predictions are implicit in our motivational framework (Figure 1) with respect to the relationship between IS characteristics and user perceptions of the IS. First, when an IS is easy to use, users are expected to perceive the IS to be efficient and less effortful. Second, the presentation format of the IS is predicted to influence the users' perceptions of the IS. Specifically, when a fit exists between the task and the method used to complete the task using the IS, users may perceive the IS to be more efficient or effective, or less effortful. Third, users may perceive an IS to be more effective if the IS does not limit the users' options (system restrictiveness). Fourth, users are expected to perceive an IS to be less effortful when the IS assists them to select and use its features during the decision-making process (decisional guidance). Fifth, when an IS provides some form of feedback (outcome, task properties, or cognitive), users are predicted to perceive the IS to be more effective. Finally, users are expected to perceive the IS to be less effortful when they are provided with a certain level of interaction with the IS. 


\section{Perceptions of the IS}

User perceptions of the IS; that is, effectiveness, efficiency, and effort is one of the two significant constructs that affects motivation to use the IS. We propose a positive relationship between perceptions of the IS and motivation to use the IS. In particular, motivation to use the IS is expected to increase when the IS is perceived to be more effective or efficient, or less effortful.

\section{Effectiveness}

User perception of the effectiveness of an IS interacts with task motivation to affect IS use. Prior research (e.g., Amer 1991; Eining \& Dorr, 1991; Hard \& Vanecek, 1996) has measured effectiveness in the context of IS use. However, limited research has examined how the characteristics of an IS impact use of the IS to do a given task. Factors, including the importance of the decision, may cause individuals to place more emphasis on effectiveness (Payne et al., 1993). Thus, effectiveness of an IS is seen as a positive factor for individuals who are motivated by the importance of the task.

\section{Efficiency}

An IS is efficient if it speeds up the decision-making process. Previous research showed that response time affected the extent of IS use. One study (Williams, 1973) examined the performance of 24 clerk typists in data entry and retrieval tasks with system response times of two, four, or eight seconds. Half of their participants were told to pay more attention to accuracy rather than the amount of time needed for task completion, while the other half was told to complete the tasks rapidly. The results showed that individuals accepted the two-second and four-second delays 98.6 and 82.6 percent of the time, respectively. However, an eight-second delay was accepted only 17.1 percent of the time. No significant difference in delay tolerance was found between individuals in the speed and accuracy conditions. A similar study (Youmans, 1981) examined the tolerance of five clerks in a variety of data entry and retrieval tasks. Participants were able to decrease system response time by one eighth if they struck a red function key. Higher tolerance of longer delays was noted for most individuals during the initial rather than later sessions. These results suggest that user perception of the efficiency of an IS may interact with task motivation to impact IS use.

Effort

Individuals experience a certain degree of effort in doing a task (Eisenberger \& Cameron, 1996) and they tend to minimize effort when they engage in the task (Todd \& Benbasat, 1992). The level of complexity of accounting and auditing decisions and judgment involves a variety of cognitive processes that are differentially sensitive to effort (Libby \& Lipe, 1992). Therefore, the extent of effort-sensitive cognitive processes required by a specific activity must be taken into consideration when establishing a relationship between increases in effort and changes in performance. The decision strategies that individuals employ to process information vary in terms of the amount of effort involved in using these strategies. For example, the additive compensatory strategy is considered to be an effortful decision strategy (Payne et al., 1993) because individuals are required to examine all the attributes for two alternatives at a given time. In contrast, the elimination-by-aspects strategy is viewed to be a less effortful decision strategy (Payne et al., 1993) because the size of the alternative set is reduced each time an attribute is selected. The reduced alternative set decreases the amount of information processing.

Todd and Benbasat (1994) extended and complemented previous studies on the role of effort and accuracy in choice tasks by examining the role of IS in reducing cognitive effort and, therefore, influencing strategy selection. They stressed the importance of understanding the role of cognitive effort because it could provide valuable insight on how IS influenced the selection of problem-solving strategies by changing the effort relationships among the component processes that made up these strategies. In addition, special features can be incorporated in an IS to change the relative effort required to implement different choice strategies; this can in turn affect strategy selection by the decision maker. Therefore, choice processes can be engineered to influence users to adopt strategies that maximize their value or utility (Todd \& Benbasat, 1994). 


\section{IS/User Characteristics}

The users' ability, knowledge, and experience in use of an IS are predicted to moderate the relationship between IS characteristics and user perceptions of the IS, especially in the case of use of a similar IS. Libby's (1992) model guides the discussion on IS/user characteristics. Specifically, in the context of our paper, ability refers to the users' ability to use an IS to process information to solve problems effectively and efficiently; knowledge refers to the information pertaining to IS use stored in memory; and experiences refer broadly to IS-related encounters that provide the users with an opportunity to learn. The extent of the users' ability, knowledge, and experience in the use of IS should be examined carefully so that insightful conclusions can be drawn on how IS characteristics affect user perceptions of the IS.

\section{Task Motivation}

Task motivation, a key construct in our motivational framework, has a significant impact on motivation to use an IS. A review of the motivation, systems, decision performance, information processing, and auditing literatures suggest that task motivation can be affected by the following five factors: user perception of the task, users' motivational orientation, decision environment, task characteristics, and task/user characteristics.

\section{Perceptions Of Task}

The characteristics of a task and the needs, goals, and values of a person determine the value of the task (Eccles et al., 1983). The four components of the Perception of Task Value scale are interest, importance, utility, and cost. The motivation theory suggests that task motivation is high when the task is perceived to be high in interest, importance or utility, or the cost of engaging in the task is low. Task motivation is low when the task is perceived to be low in interest, importance or utility, or the cost of engaging in the task is high. The Perception of Task Value scale can be used as a manipulation check on task motivation.

\section{Interest}

Individuals experience interest when their needs and desires are integrated with the activity. From this perspective, interest is the driving mechanism for all actions, including cognitive activity (Piaget, 1981). A person is said to be experientially interested when a certain quality of attention and sense of delight is present. Interest leads to the performance of intrinsically motivated behaviors (Deci, 1998). In this respect, interest and intrinsic motivation are considered to be synonymous $^{1}$ (Tobias, 1994). Consistent with the definition offered by Sansone and Smith (2000), we define $\operatorname{task}^{2}$ (intrinsic) motivation as a person's experience of interest in an activity (i.e., use of an IS to do a task).

\section{Importance}

The importance component pertains to the importance of performing well in an activity (Eccles et al., 1983). Importance is also related to the relevance of engaging in an activity to either confirm or disconfirm salient features of a person's actual or ideal self-schema (Wigfield \& Eccles, 1992). A task is deemed to be high in importance if it allows individuals to confirm salient attributes of their self-schemata (e.g., competence in the domains of sports or arts) (Wigfield \& Eccles, 1992). When users perceive the task to be personally important, they become motivated by the task and this leads to increased task motivation.

\section{Utility}

The utility component refers to the importance of a task for the pursuance of a variety of long-term or shortterm goals without any regard for a person's interest in the task (Wigfield \& Eccles, 1992). The utility component relates to a person's extrinsic reasons for engaging in an activity; specifically, a person may engage in a task not for its own sake but to obtain desired goals (Wigfield \& Eccles, 1992). Utility can also be viewed as perceived usefulness of the task for goal attainment (e.g., a person's extrinsic belief about how the task can assist her to attain specific goals such as career prospects or outperforming others) (Pintrich \& Schrauben, 1992). 
Cost

The cost of engaging in a task is affected by the: (1) amount of effort necessary for succeeding, (2) opportunity cost of engaging in the activity, and (2) anticipated emotional states such as performance anxiety, fear of failure, or fear of the negative consequences of success (Wigfield \& Eccles, 1992). A negative relationship is proposed to exist between the value of the task and the cost/benefit ratio in terms of the amount of effort required for doing well in the task (Eccles et al., 1983). The opportunity cost of a task refers to the time lost for engaging in other valued alternatives (Eccles et al., 1983). A person may experience anxiety, fear of failure, or fear of the negative consequences of success in the course of a task engagement (Eccles, 1987).

\section{Motivational Orientation}

A person may be intrinsically motivated (i.e., do a task for the sake of interest), extrinsically motivated (i.e., do a task for the sake of extrinsic incentives) or have no motivation for doing a task (Amabile, 1988). Individuals have a desire to perform well either for internal (e.g., interest or enjoyment) or external (e.g., to impress others or to attain goals) reasons. A person's baseline attitude toward an activity can be considered as a trait (Amabile, 1983). This individual can walk into a situation with a specific motivational orientation. The type of motivational orientation (i.e., intrinsic, extrinsic, or both) determines a person's initial task motivation. Motivational orientation has an impact on the final and type of motivation in a specific task. Researchers (deCharms, 1968; Deci \& Ryan, 1985; Harter, 1981) have treated the intrinsic-extrinsic motivational orientation as a stable individual difference variable. The Work Preference Inventory (WPI) was developed to assess the intrinsic and extrinsic motivation of individuals (Amabile et al., 1994). This scale directly assesses the intrinsic and extrinsic motivation of individuals, assumes the coexistence of intrinsic and extrinsic motivation, and incorporates a wide range of cognitions and emotions proposed to be part of intrinsic and extrinsic motivation. The impact of motivational orientation (a trait variable) on task motivation (a state variable) should be examined.

\section{Decision Environment}

The decision-making process is frequently influenced by factors in the environment. These factors have an impact on the behaviors of decision makers. Factors in the decision environment (i.e., extrinsic incentives, justification, accountability, and time constraint) have an effect on task motivation. Task motivation is expected to be high when individuals are (a) provided with extrinsic incentives for doing a task, (b) required to justify their performance in the task, (c) held accountable for the outcome of their decision performance, or (d) required to complete the task in a specific time frame. Task motivation is predicted to be low when the above decision environmental factors are absent.

\section{Extrinsic Incentives}

Prior research (e.g. Awasthi \& Pratt, 1990; Hunton \& McEwen, 1997; Klein, Goodhue, \& Davis, 1997) has examined the impact of extrinsic incentives on decision performance. Monetary incentives were found to induce participants to spend more time on the task (Awasthi \& Pratt, 1990); motivational incentives were reported to increase their tendency in making optimistic earnings forecasts (Hunton \& McEwen, 1997); and goals and incentives were said to influence decision performance (Klein et al., 1997).

A meta-analysis of 128 well-controlled experiments was conducted to examine the relationship between extrinsic incentives and intrinsic motivation (Deci, Koestner, \& Ryan, 1999). The findings indicate significant and consistent negative impact of extrinsic incentives on intrinsic motivation for interesting activities. The types of reward structures include task noncontingent, task-contingent, and performance-contingent (Ryan, Mims, \& Koestner, 1983). Task noncontingent rewards are given simply for participation in the study, without consideration of actual engagement in the task (Deci et al., 1999). An example of a task noncontingent reward was paying individuals $\$ 2$ simply for their participation in the study without any regard for what they did during the experiment (Deci, 1972). Task noncontingent rewards are not expected to affect intrinsic motivation because participants are not required to perform well in the activity, complete the task, or even do the task (Deci et al., 1999). Task-contingent rewards are 
administered only after the individuals actually do or complete the task (Deci et al., 1999). Task-contingent rewards are further distinguished into two subcategories; namely, completion-contingent and engagement-contingent (Deci et al., 1999). Completion-contingent rewards are given only upon explicit completion of the target activity; engagementcontingent rewards are administered simply for engagement in the task, without consideration of completion of the task. An example of a completion-contingent reward is requiring participants to work on four variations of a threedimensional puzzle and giving them $\$ 1$ for each puzzle completed in the specified time (Deci, 1971). An example of an engagement-contingent reward is telling the participants that they would receive a reward for doing a series of hidden-figures puzzles (Ryan et al., 1983). These individuals were not aware of whether they had done well or completed the activity because they had no knowledge of the number of hidden figures in each drawing (Deci et al., 1999). Both completion-contingent and engagement-contingent rewards are found to have a similar undermining effect on free-choice intrinsic motivation and self-reported interest. Performance-contingent rewards are administered when participants excelled in the activity or met a specific standard (e.g., performing better than $90 \%$ of the participants). Performance-contingent rewards have a significant negative impact on free-choice behavior but not self-reported interest. Performance contingent rewards are the most detrimental type of reward, especially when the rewards are experienced as controlling. In the case of performance-contingent rewards experienced as informational, intrinsic motivation may be less undermined or possibly even enhanced (Ryan et al., 1983).

\section{Justification Versus Accountability}

Decision makers are constantly faced with the need to justify their decisions or to account to their sources for their decisions. The impact of justification and accountability on the decision makers' behaviors has been studied extensively in the judgment and decision making literature (e.g., Cuccia, Hackenbrack, \& Nelson, 1995; Hackenbrack \& Nelson, 1996; Johnson \& Kaplan, 1991; Lord, 1992). Existing studies have used justification and accountability interchangeably. One explanation for the lack of distinction between these two constructs is the expectation of similar effects of justification and accountability on behaviors. Justification is defined as the need to justify one's decisions (Arnold, 1997). Since this definition is very similar to the definition of accountability offered by Kennedy (1993), the distinction between justification and accountability is unclear although these are two distinct constructs (Johnson \& Kaplan, 1991).

Justification refers to the process that a person goes through to provide support or reasons for her behavior. Since a person only needs to provide justification for her behavior, she is not held responsible for the outcome as long as she is able to provide reasonable justification for her behavior. In contrast, when a person is held accountable for her behavior, she is responsible for the outcome; that is, this individual will either be rewarded for positive outcome or punished for negative outcome. In this respect, two definitions of justification offered in the literature may assist us in understanding the distinction between justification and accountability; that is, justification is "the act of providing evidence to support one's judgments or decisions" (Peecher, 1996, p. 126), or "the actual physical and/or mental process of explaining a judgment" (Johnson \& Kaplan, 1991, p. 98).

Accountability is a "pre-existing expectation that an individual may be called on to justify his/her judgments to a significant other" (Johnson \& Kaplan, 1991, p. 98). In other words, accountability is present when a person is held responsible for the outcome. In most practical business contexts, individuals are frequently expected to account for their decisions both to themselves and to others (Arnold, 1997). Some research evidence suggests that accountability can have an effect on decisions (Arnold, 1997). For example, MBA students showed significant recency effects (i.e., they placed more weight on evidence received later in a sequence) whereas auditor participants did not; however, no recency effects occurred when accountability was imposed on the MBA students (Kennedy, 1993).

\section{Time Constraint}

Time has frequently been used as a surrogate measure for cognitive effort or decision performance in the IS literature (Brown \& Eining, 1996). Time constraint can affect task motivation. For example, individuals in the highest time constraint condition exhibited more consistent performance than other groups when information load and presentation format in the context of a simple audit task was examined (Davis, 1994). The more consistent results 
obtained in this study can be attributed to the use of relatively simple strategies by participants to reduce the effects of time constraint in the decision environment (Brown \& Eining, 1996). In a study on the effect of time pressure on judgment as opposed to choice tasks, time constraint had a significant negative impact on judgment decision quality than choice tasks (Smith, Arnold, \& Sutton, 1997).

\section{Task Characteristics}

Task motivation is affected by characteristics of the task such as complexity, difficulty, structure, ambiguity, and novelty. Task motivation is expected to be high when the task is less complex, difficult, or ambiguous or has more structure or novelty. The impact of task characteristics on task motivation is dependent on a person's motivational orientation. An intrinsically oriented individual may prefer a task that has more complexity, difficulty or ambiguity, less structure, or more novelty. An extrinsically oriented individual may prefer a task that has less complexity, difficulty or ambiguity, more structure or less novelty.

\section{Complexity}

Task complexity can occur at the stages of input, processing, or output and may relate to either the amount or clarity of information (Bonner, 1994). At the input stage, the amount of information can vary in terms of the number of alternatives, the number of attributes on which each alternative is compared, and attribute redundancy. Clarity of input may be reduced by relevant cues that are not specified or measured well, inconsistency between presented and stored cues, and presentation format. Processing can be complex when the amount of input increases, the number of procedures increases, procedures are not well specified, and the procedures are dependent on one another. Internally consistent cues or low or negative cue validities in nonlinear functions may reduce clarity and increase processing complexity. Complexity may also increase with the number of goals or solutions per alternative (i.e., the amount of output), and indefinite or unspecified goals (i.e., lack of clarity in output) created by the environment or by a person's lack of familiarity with the goals (Bonner, 1994).

\section{Difficulty}

Difficulty can be defined as the amount of attentional capacity or mental processing required for doing a task (Kahneman, 1973). Task difficulty increases with increased similarity of the alternatives and this hampers a person's ability in discriminating the alternatives from one another (Stone \& Kadous, 1997). A task is high in difficulty when a person perceives a tremendous amount of cognitive effort in information processing. The level of difficulty of a specific task has an effect on task motivation. A person is unlikely to be motivated by the task when she perceives the task to be difficult. An individual may become more motivated by the task when the task is perceived to be low in difficulty. Task complexity and difficulty are not synonymous; that is, a complex task may involve an increased number of steps but it may not require increased cognitive effort to process the information (i.e., the task can be low in difficulty).

\section{Structure}

Structure refers to the specification level of what is to be accomplished in a given task (Simon, 1973). A task can be classified on a continuum that indicates the degree of structure. A highly structured task requires a person to follow a predefined procedure for completing the activity. A task is highly unstructured when a predefined procedure for doing the activity is absent.

\section{Ambiguity}

IS use was reported to be influenced by task ambiguity (Brown \& Jones, 1998). Although no significant difference in decision performance was found for both the IS and non-IS groups in relatively unambiguous decision situations, the IS group outperformed the no-IS group in relatively ambiguous decision contexts (Brown \& Eining, 1996). Research is needed to provide insight into the impact of task ambiguity on task motivation and motivation to use an IS. 
Novelty

Novelty is a task characteristic that affects task motivation. Most conceptual definitions of creativity include the novelty characteristic (Hennessey \& Amabile, 1988). Creativity is enhanced when novelty is present in a task. Since individuals are most creative when they are motivated by the task, task motivation may further increase when the task entails a certain degree of novelty. Although the novelty construct may have a short-term positive impact on task motivation, research is required to enhance our understanding on the effect of the novelty characteristic on task motivation.

\section{Task/User Characteristics}

Task/user characteristics refer to the users' ability, knowledge, and experience in a given task. These characteristics are discussed in the context of Libby's model. Ability relates to the users' capacity to engage in information processing activities that lead to problem solving; knowledge pertains to the information stored in memory; and experiences refer broadly to the task-related encounters that provide users with an opportunity to learn (Libby, 1992). Our motivational framework (Figure 1) suggests that the users' ability, knowledge, and experience in a task have a positive effect on task motivation. Users with high abilities are expected to be high in task motivation because their increased capacity in information processing results in effective and efficient problem solving. Users with low abilities are predicted to be low in task motivation because of their limited capacity in information processing which in turn impairs their ability to solve problems. Users who are knowledgeable may possess essential information in memory that allows them to do a task effectively and efficiently; as such, their task motivation is expected to be high. Less knowledgeable users may be low in task motivation because they do not have the necessary information stored in memory that permits them to carry out the task effectively and efficiently. Finally, experienced users with task-related encounters are stimulated by the opportunities to learn and this increases their task motivation. Since less experienced users tend to have fewer task-related encounters and fewer opportunities to learn, their task motivation may be low.

\section{Motivation To Use An IS}

Researchers have conducted studies to enhance understanding on why and when users may become motivated to use an IS. Use of an expert system was found to enhance the engagement of users and increase their use of the IS (Eining et al., 1997). Passive IS use was reported to lead to deficient user behavior (Glover, Prawitt, \& Spilker, 1997). This effect can be attributed to lack of motivation to use the IS. The Perceptions of Task Value scale (developed by Eccles et al., 1983) can be modified to obtain the Perception of IS scale to measure a user's motivation to use an IS. The four components in the scale include interest, importance, utility, and cost. Although these components can be differentiated, it is not easy to distinguish their relations (Jacobs \& Eccles, 2000). The characteristics of an IS and the needs, goals, and values of the users may affect the extent of IS usage. We theorize that motivation to use an IS is high when the IS is perceived to be high in interest, importance or utility, or opportunity cost of using the IS is low. Motivation to use an IS is expected to be low when the IS is perceived to be low in interest, importance or utility, or the cost of using the IS is high.

\section{IS Use}

The theory of reasoned action (TRA) and the technology acceptance model (TAM) are widely used to predict and explain user acceptance and rejection of computer-based technology (Davis et al., 1989). TRA suggests that individuals would use IS if they perceive benefits associated with such usage. TAM, an adaptation of TRA, is designed for modeling user acceptance of IS (Davis, 1989). A general measure of computer self-efficacy was developed and validated to explain IS usage (Compeau \& Higgins, 1995). The findings provide support for this model and the social cognitive theory perspective on behavior. Additional constructs and theories are needed to help explain IS usage (Compeau \& Higgins, 1995). Indeed, research has focused extensively on the effectiveness of decision rules and limited research is available to facilitate understanding on how decision rule use can be increased to improve decision performance (Davis \& Kottemann, 1995). 


\section{Decision Performance}

Despite numerous studies that have attempted to explain decision performance and the wide variety of independent measures used (e.g., Amer, 1991; Eining \& Dorr, 1991; Hunton \& McEwen, 1997; Tuttle \& Stocks, 1997; Wright \& Wright, 1997), a significant amount of variance in decision performance still remains unexplained. The mixed findings reported in the decision performance literature provide support for this contention. For example, screen layouts did not affect productivity or user satisfaction (Gibson, 1994) and feedback did not have a significant impact on decision performance (Eining \& Dorr, 1991). These studies suggest that not all potentially relevant variables have been identified and their impact on decision performance evaluated in the current literature. In addition, few reliable measures of the quality of decision performance currently exist in the IS literature. The reason could be that it is difficult to assess the quality of a choice, decision, or judgment until after a certain period of time has elapsed.

\section{FUTURE RESEARCH}

An important benefit of IS is the reduction of cognitive effort in terms of ease in gathering and organizing information for effective and efficient processing. However, rather than augmenting processing capacity, IS has been found to replace the effort expended by users (Todd \& Benbasat, 1992). This finding is not surprising because although the IS reduces the effort required to process information, this does not necessarily translate into increased amount of information processed by the users if adequate motivation is lacking. Further, the findings on the impact of task complexity on decision performance have not been consistent. High task complexity has been reported to result in both impaired (e.g., Chang, Ho, \& Liao, 1997; Swink \& Speier, 1999) and improved (e.g. Asare \& McDaniel, 1996; Bolt, Killough, \& Koh 2001; Marshall \& Bryd, 1998) decision performance. Inconclusive results have also been reported on the impact of extrinsic incentives on decision performance. Although motivation researchers (e.g., Deci, 1971; Ryan et al., 1983) demonstrated that intrinsic motivation was negatively affected in situations where completion-contingent, engagement-contingent, and performance-contingent incentives were administered, IS researchers found that goals and incentives induced individuals to spend more time on the task (Awasthi \& Pratt, 1990); increased their tendency in making optimistic earnings forecasts (Hunton \& McEwen, 1997); and improved decision performance (Klein, Goodhue, \& Davis, 1997). Our motivational framework can help explain the inconsistent findings reported by prior research. We identify the significant role of the motivation factor in explaining IS use and decision performance. Motivation is separated into two key components; namely, task motivation and motivation to use an IS to do the task. Separation of these two effects will assist researchers in identifying the underlying reasons for lack of IS use; that is, lack of motivation in a given task or lack of motivation to use an IS to do the task. The motivation theory can provide insight into the findings by Todd and Benbasat (1992) on why users are not translating the effort savings derived from use of the IS into increased information processing. The reason could be that the users are not motivated by the task or are not motivated to use the IS to do the task.

Our motivational framework proposes a new stream of research for understanding IS use and decision performance. Future research should examine factors that affect task motivation. First, components of the perceptions of task construct (i.e., interest, importance, utility, and cost) can be manipulated to obtain a measure of task motivation. Second, research attention should be directed at studying the impact of the users' motivational orientation, decision environmental factors, task characteristics, and user characteristics on task motivation. Further, future work can examine how perceived effectiveness or efficiency of the IS or perceived effort in using the IS (i.e. user perceptions of the IS) interact to impact motivation to use the IS. Additional research can shed light on how IS characteristics can be manipulated to obtain favorable user perceptions of the IS to increase motivation to use the IS. Finally, researchers can facilitate understanding on how task motivation can be promoted to increase motivation to use the IS, actual IS use, and improved decision performance.

\section{REFERENCES}

1. Adams, D.A., Nelson, R.R., \& Todd, P.A. (1992). Perceived usefulness, ease of use, and usage of information technology: A replication. MIS Quarterly, 227-247. 
2. Amabile, T. M. (1983). The social psychology of creativity. New York: Springer-Verlag.

3. Amabile, T. M. (1988). A model of creativity and innovation in organizations. Research in Organizational Behavior, 10, 123-167.

4. Amabile, T. M., Hill, K. G., Hennessey, B. A., \& Tighe, E. M. (1994). The Work Preference Inventory: Assessing intrinsic and extrinsic motivational orientations. Journal of Personality and Social Psychology, 66 (5), 950-967.

5. Amer, T. (1991). An experimental investigation of multi-cue financial information display and decision making. Journal of Information Systems, 5, 18-34.

6. Arnold, V. (1997). Judgment and decision making, part I: The impact of environmental factors. In V. Arnold \& S. G. Sutton (Eds.), Behavioral accounting research foundations and frontiers (pp. 164-187). Sarasota, FL: American Accounting Association.

7. Asare, S. K., \& McDaniel, L. S. (1996). The effects of familiarity with the preparer and task complexity on the effectiveness of the audit review process. Accounting Review, 71, 139-159.

8. Awasthi, V., \& Pratt, J. (1990). The effects of monetary incentives on effort and decision performance: The role of cognitive characteristics. Accounting Review, 65 (4), 797-811.

9. Ajzen, I., \& Fishbein, M. (1980). Understanding attitudes and predicting social behavior, Prentice Hall, Englewood Cliffs, NJ.

10. Balakrishnan, P.V.S., \& Jacob, V.S. (1995). Triangulation in decision support systems: Algorithms for product design. Decision Support Systems, 14, 313-327.

11. Becker, D. A. (1997). The effects of choice on auditors' intrinsic motivation and performance. Behavioral Research in Accounting, 9, 1-19.

12. Boatsman, J. R., Moeckel, C., \& Pei, B. K. W. (1997). The effects of decision consequences on auditors' reliance on decision aids in audit planning. Organizational Behavior and Human Decision Processes, 71 (2), 211-247.

13. Bolt, M. A., Killough, L. N., \& Koh, H. C. (2001). Testing the interaction effects of task complexity in computer training using the social cognitive model. Decision Sciences, 32, 1-20.

14. Bonner, S. E. (1994). A model of the effects of audit task complexity. Accounting, Organizations and Society, 19 (3), 213-234.

15. Brown, D. L., \& Eining, M. M. (1996). The role of decision aids in accounting: A synthesis of prior research. Advances in Accounting Information Systems, 4, 305-332.

16. Brown, D. L., \& Jones, D. R. (1998). Factors that influence reliance on decision aids: A model and an experiment. Journal of Information Systems, 12, 75-94.

17. Butler, S. A. (1985). Application of a decision aid in a judgmental evaluation of substantive test of details samples. Journal of Accounting Research, 23, 2.

18. Chang, J. C., Ho, J. L. Y., \& Liao, W. M. (1997). The effects of justification, task complexity and experience/training on problem-solving performance. Behavioral Research in Accounting, 9, 98-116.

19. Chau, P.Y.K. (1996). An empirical assessment of a modified technology acceptance model. Journal of Management Information Systems, 13, 2.

20. Chenoweth, T., Dowling, K.L., St. Louis, R.D. (2003). Convincing DSS users that complex models are worth the effort. Decision Support Systems, 1050, 1-12.

21. Cheung, W., Chang, M.K., \& Lai, V.S. (2000). Prediction of Internet and World Wide Web usage at work: A test of an extended Triandis model. Decision Support Systems, 30, 83-100.

22. Chu, P. C., \& Spires, E. E. (2001). Does time constraint on users negate the efficacy of decision support systems? Organizational Behavior and Human Decision Processes, 85 (2), 226-249.

23. Compeau, D. R., \& Higgins, C. A. (1995). Computer self-efficacy: Development of a measure and initial test. MIS Quarterly, 19 (2), 189-211.

24. Cuccia, A. D., Hackenbrack, K., \& Nelson, M. W. (1995). The ability of professional standards to mitigate aggressive reporting. The Accounting Review, 70, 227-248.

25. Davis, C. E. (1994). Presentation format, information load, and time pressure effects on the consistent application of a decision rule. Working paper, Baylor University, Waco, TX.

26. Davis, F. D. (1989). Perceived usefulness, perceived ease of use, and user acceptance of information technology. MIS Quarterly, 13 (3), 319-339. 
27. Davis, F. D., Bagozzi, R. P., \& Warshaw, P. R. (1989). User acceptance of computer technology: A comparison of two theoretical models. Management Science, 35 (8), 982-1003.

28. Davis, F. D., Bagozzi, R. P., \& Warshaw, P. R. (1992). Extrinsic and intrinsic motivation to use computers in the workplace. Journal of Applied Social Psychology, 22 (14), 1111-1132.

29. Davis, F. D., \& Kottemann, J. E. (1995). Determinants of decision rule use in a production planning task. Organizational Behavior and Human Decision Processes, 63 (2), 145-157.

30. deCharms, R. (1968). Personal causation. New York: Academic Press.

31. Deci, E. L. (1971). Effects of externally mediated rewards on intrinsic motivation. Journal of Personality and Social Psychology, 18, 105-115.

32. Deci, E. L. (1972). Effects of contingent and non-contingent rewards and controls on intrinsic motivation. Organizational Behavior and Human Performance, 8, 217-229.

33. Deci, E. L. (1998). The relation of interest to motivation and human needs - the self-determination theory viewpoint. In L. Hoffmann, A. Krapp, K. Renninger, \& J. Baumert (Eds.), Interest and learning: Proceedings of the Seeon Conference on Interest and Gender (pp. 146-163). Kiel, Germany: IPN.

34. Deci, E. L., Koestner, R., \& Ryan, R. M. (1999). A meta-analytic review of experiments examining the effects of extrinsic rewards on intrinsic motivation. Psychological Bulletin, 125 (6), 627-668.

35. Deci, E. L., \& Ryan, R. M. (1985). The General Causality Orientations Scale: Self-determination in personality. Journal of Research in Personality, 19, 109-134.

36. Eccles, J. S. (1987). Gender roles and women's achievement-related decisions. Psychology of Women Quarterly, 11, 135-172.

37. Eccles (Parsons), J. S., Adler, T. F., Futterman, R., Goff, S. B., Kaczala, C. M., Meece, J. L., \& Midgley, C. (1983). Expectancies, values, and academic behaviors. In J. T. Spence (Ed.), Achievement and achievement motives (pp. 75-146). New York: W. H. Freeman and Company.

38. Eining, M. M., \& Dorr, P. B. (1991). The impact of expert system usage on experiential learning in an auditing setting. Journal of Information Systems, 5, 1-16.

39. Eining, M. M., Jones, D. R., \& Loebbecke, J, K. (1997). Reliance on decision aids: An examination of auditors' assessment of management fraud. Auditing: A Journal of Practice and Theory, 16 (2), 1-19.

40. Eisenberger, R., \& Cameron, J. (1996). Detrimental effects of reward: Reality or myth? American Psychologist, 51 (11), 1153-1166.

41. Farivari, R., \& Levy, I. (1983). A test of patience. Research project report to James Foley, Computer Science Dept., George Washington University, Washington, DC.

42. Forgionne, G., \& Kohli R. (1996). HMSS: A management support system for concurrent hospital decisionmaking. Decision Support Systems 16 (3), 209-229.

43. Gibson, D. L. (1994). The effects of screen layout and feedback type on productivity and satisfaction of occasional users. Journal of Information Systems, 8 (2), 105-114.

44. Glover, S. M., Prawitt, D. F., \& Spilker, B. C. (1997). The influence of decision aids on user behavior: Implications for knowledge acquisition and inappropriate reliance. Organizational Behavior and Human Decision Processes, 72 (2), 232-255.

45. Hackenbrack, K., \& Nelson, M. W. (1996). Auditors incentives and their application of financial accounting standards. The Accounting Review, 71, 43-59.

46. Hard, N. J., \& Vanecek, M. T. (1991). The implications of tasks and format on the use of financial information. Journal of Information Systems, 5, 35-49.

47. Harter, S. (1981). A new self-report scale of intrinsic versus extrinsic orientation in the classroom: Motivational and informational components. Developmental Psychology, 17 (3), 300-312.

48. Hennessey, B. A., \& Amabile, T. M. (1988). In R. J. Sternberg (Ed.), The nature of creativity: Contemporary psychological perspectives (pp. 11-38). New York: Cambridge University Press.

49. Hirst, M. K., \& Luckett, P. F. (1992). The relative effectiveness of different types of feedback in performance evaluation. Behavioral Research in Accounting, 4, 1-22.

50. Hunton, J. E., \& McEwen, R. A. (1997). An assessment of the relation between analysts' earnings forecast accuracy, motivational incentives and cognitive information search strategy. Accounting Review, 72 (4), 497-515.

51. Igbaria, M., Zinatelli, N., Cragg, P., \& Cavaye, A. L. M. (1997). ersonal computing acceptance factors in small firms: A structural equation model. MIS Quarterly, 21 (3), 279-305. 
52. Jarvenpaa, S. L. (1989). The effect of task demands and graphical format on information processing strategies. Management Science, 35, 285-303.

53. Johnson, V. E., \& Kaplan, S. E. (1991). Experimental evidence on the effects of accountability on auditor judgments. Auditing: A Journal of Practice \& Theory, 10 (Supplement), 98-107.

54. Kahneman, D. (1973). Attention and Effort, Englewood Cliffs, NJ: Prentice Hall.

55. Kanungo, S., Sharma S., Jain P.K. (2001). Evaluation of a decision support system for credit management decisions. Decision Support Systems, 30, 419-436.

56. Kasper, G. M. (1996). A theory of decision support system design for user calibration. Information Systems Research, 7 (2), 215-232.

57. Keen, P.G.W., \& Scott-Morton, M.S. (1978). Decision support systems: An organizational perspective, Addison-Wesley, Reading, MA.

58. Keil, M. (1995). Pulling the plug: Software project management and the problem of project escalation. MIS Quarterly, 19, 421-447.

59. Kennedy, J. (1993). Debiasing audit judgment with accountability: A framework and experimental results. Journal of Accounting Research, 31 (2), 231-245.

60. Klein, B. D., Goodhue, D. L, \& Davis, G. B. (1997). Can humans detect errors in data? Impact of base rates, incentives, and goals. MIS Quarterly, 21 (2), 169-194.

61. Kohli, R., Devaraj, S. (2002). Contribution of institutional DSS to organizational performance: Evidence from a longitudinal study. Decision Support Systems, 1045, 1-16.

62. Kruglanski, A. W., Friedman, I., \& Zeevi, G. (1971). The effects of extrinsic incentive on some qualitative aspects of task performance. Journal of Personality, 39, 606-617.

63. Lederer, A.L., Maupin, D.J., Sena, M.P., \& Zhuang, Y. (2000). The technology acceptance model and the World Wide Web. Decision Support Systems, 29, 269-282.

64. Lepper, M. R., Greene, D., \& Nisbett, R. E. (1973). Undermining children's intrinsic interest with extrinsic reward: A test of the "overjustification" hypothesis. Journal of Personality and Social Psychology, 28 (1), 129-137.

65. Libby, R. (1992). The role of knowledge and memory in audit judgment. In R. H. Ashton and A. H. Ashton (Eds.), Judgment and Decision-making Research in Accounting and Auditing (pp. 176-206). New York: Cambridge University Press.

66. Libby, R., \& Lipe, M. G. (1992). Incentives, effort, and the cognitive processes involved in accountingrelated judgments. Journal of Accounting Research, 30 (2), 249-273.

67. Libby, R., \& Luft, J. (1993). Determinants of judgment performance in accounting settings: Ability, knowledge, motivation, and environment. Accounting, Organizations and Society, 18 (5), 425-450.

68. Lord, A. T. (1992). Pressure: A methodological consideration for behavioral research in auditing. Auditing: A Journal of Practice and Theory, 90-108.

69. Marshall, T. E., \& Byrd, T. A. (1998). Perceived task complexity as a criterion for information support. Information \& Management, 34, 251-263.

70. Payne, J. W., Bettman, J. R., \& Johnson, E. J. (1993). The adaptive decision maker. Cambridge University Press.

71. Peecher, M. E. (1996). The influence of auditors' justification processes on their decisions: A cognitive model and experimental evidence. Journal of Accounting Research, 34 (1), 125-140.

72. Piaget, J. (1981). Intelligence and affectivity: Their relationship during child development. Palo Alto: Annual Reviews. (Original work published in 1954).

73. Pintrich, P. R., \& Schrauben, B. (1992). Students' motivational beliefs and their cognitive engagement in classroom academic tasks. In D. H. Schunk \& J. L. Meece (Eds.), Student Perceptions in the Classroom (pp. 149-183). Hillsdale, NJ: Erlbaum.

74. Roth, E. M., Bennett, K. B., \& Woods, D. D. (1987). Human interaction with an "intelligent" machine. International Journal of Man-Machine Studies, 27, 479-525.

75. Roy, M. C., \& Lerch, J. F. (1996). Overcoming ineffective mental representations in base-rate problems. Information Systems Research, 7 (2), 233-247.

76. Ryan, R. M., Mims, V., \& Koestner, R. (1983). Relation of reward contingency and interpersonal context to intrinsic motivation: A review and test using cognitive evaluation theory. Journal of Personality and Social Psychology, 45, 736-750. 
77. Sansone, C., \& Smith, J. L. (2000). Interest and self-regulation: The relation between having to and wanting to. In C. Sansone \& J. M. Harackiewicz (Eds.), Intrinsic and extrinsic motivation: The search for optimal motivation and performance (pp. 341-372). San Diego: Academic Press.

78. Sichel, D. E. (1997). The computer revolution: An economic perspective. The Brookings Institution, Washington, D. C.

79. Silver, M. S. (1988). On the restrictiveness of decision support systems. In R. M. Lee, A. M., McCosh, \& P. Migliarese (Eds.), Organizational decision support systems, Proc. IFIP WG 8.3 Working Conf., (pp. 259270). North Holland, Como, Italy: Elsevier Science Publishers B. V.

80. Silver, M. S. (1990). Decision support systems: Directed and nondirected change. Information Systems Research, 1 (1), 47-70.

81. Simon, H. A. (1973). The structure of ill structured problems. Artificial Intelligence, 4, 181-201.

82. Singh, D.T. (1998). Incorporating cognitive aids into decision support systems: The case of the strategy execution process. Decision Support Systems, 24, 145-163.

83. Smith, C. A. P., Arnold, V., \& Sutton, S. G. (1997). The impact of time pressure on decision-making for choice and judgment tasks. Accounting and Business Review, 365-383.

84. Stock, D., \& Watson, C. J. (1984). Human judgment accuracy, multidimensional graphics, and human versus models. Journal of Accounting Research, 22, 192-206.

85. Stone, D. N. (1995). The joint effects of DSS feedback and users' expectations on decision processes and performance. Journal of Information Systems, 9 (1), 23-41.

86. Stone, D. N., \& Kadous, K. (1997). The joint effects of task-related negative affect and task difficulty in multiattribute choice. Organizational Behavior and Human Decision Processes, 70 (2), 159-174.

87. Swanson, E. B. (1988). Information system implementation: Bridging the gap between design and utilization. Homewood, IL: Irwin.

88. Swink, M., \& Speier, C. (1999). Presenting geographic information: Effects of data aggregation, dispersion, and users' spatial orientation. Decision Sciences, 30, 169-195.

89. Teo, T.S.H., Lim, V.K.G., \& Lai, R.Y.C. (1999). Intrinsic and extrinsic motivation in Internet usage. Omega, 27, 25-37.

90. Thomas, J. D. E. (1996). The importance of package features and learning factors for ease of use. International Journal of Human-Computer Interaction, 8 (2), 165-187.

91. Tobias, S. (1994). Interest, prior knowledge, and learning. Review of Educational Research, 64, $37-54$.

92. Todd, P., \& Benbasat, I. (1992). The use of information in decision making: An experimental investigation of the impact of computer-based decision aids. MIS Quarterly, 16, 373-393.

93. Todd, P., \& Benbasat, I. (1994). The influence of decision aids on choice strategies: An experimental analysis of the role of cognitive effort. Organizational Behavior and Human Decision Processes, 60, 36-74.

94. Todd, P., \& Benbasat, I. (1996). The effects of decision support and task contingencies on model formulation: A cognitive perspective. Decision Support Systems, 17, 241-252.

95. Tuttle, B., \& Stocks, M. H. (1997). he effects of task information and outcome feedback on individuals' insight into their decision models. Decision Sciences, 28 (2), 421-442.

96. Tuttle, B., \& Stocks, M. H. (1998). The use of outcome feedback and task property information by subjects with accounting-domain knowledge to predict financial distress. Behavioral Research in Accounting, 10, 76108 .

97. Umanath, N. S., Scamell, R. W., \& Das, S. R. (1990). An examination of two screen/report design variables in an information recall context. Decision Sciences, 21, 216-240.

98. Venkatesh, V. (1999). Creation of favorable user perceptions: Exploring the role of intrinsic motivation. MIS Quarterly, 23 (2), 239-260.

99. Venkatesh, V., \& Speier, C. (1999). Computer technology training in the workplace: A longitudinal investigation of the effect of mood. Organizational Behavior and Human Decision Processes, 79 (1), 1-28.

100. Venkatesh, V., \& Davis, F. D. (2000). A theoretical extension of the technology acceptance model: Four longitudinal field studies. Management Science, 46 (2), 186-204.

101. Vessey, I. (1991). Cognitive fit: A theory-based analysis of the graphs versus tables literature. Decision Sciences, 22, 219-240.

102. Vessey, I., \& Galletta, D. (1991). Cognitive fit: An empirical study of information acquisition. Information Systems Research, 2 (1), 63-84. 
103. Wigfield, A., \& Eccles, J. S. (1992). The development of achievement task values: A theoretical analysis. Developmental Review, 12, 265-310.

104. Williams, C. M. (1973). System response time: A study of users' tolerance. IBM Advanced Systems Development Division Technical Report, 17-272, 1-28.

105. Wright, S., \& Wright, A. M. (1997). The effect of industry experience on hypothesis generation and audit planning decisions. Behavioral Research in Accounting, 9, 273-294.

106. Yang, H., \& Yoo, Y. (Forthcoming). It's all about attitude: Revisiting the technology acceptance model. Decision Support Systems.

107. Youmans, D. M. (1981). User requirements for future office workstations with emphasis on preferred response times. IBM United Kingdom Laboratories, Report HF058, Hursley Park, England. 
Figure 1: A Motivational Framework for Understanding IS Use and Decision Performance

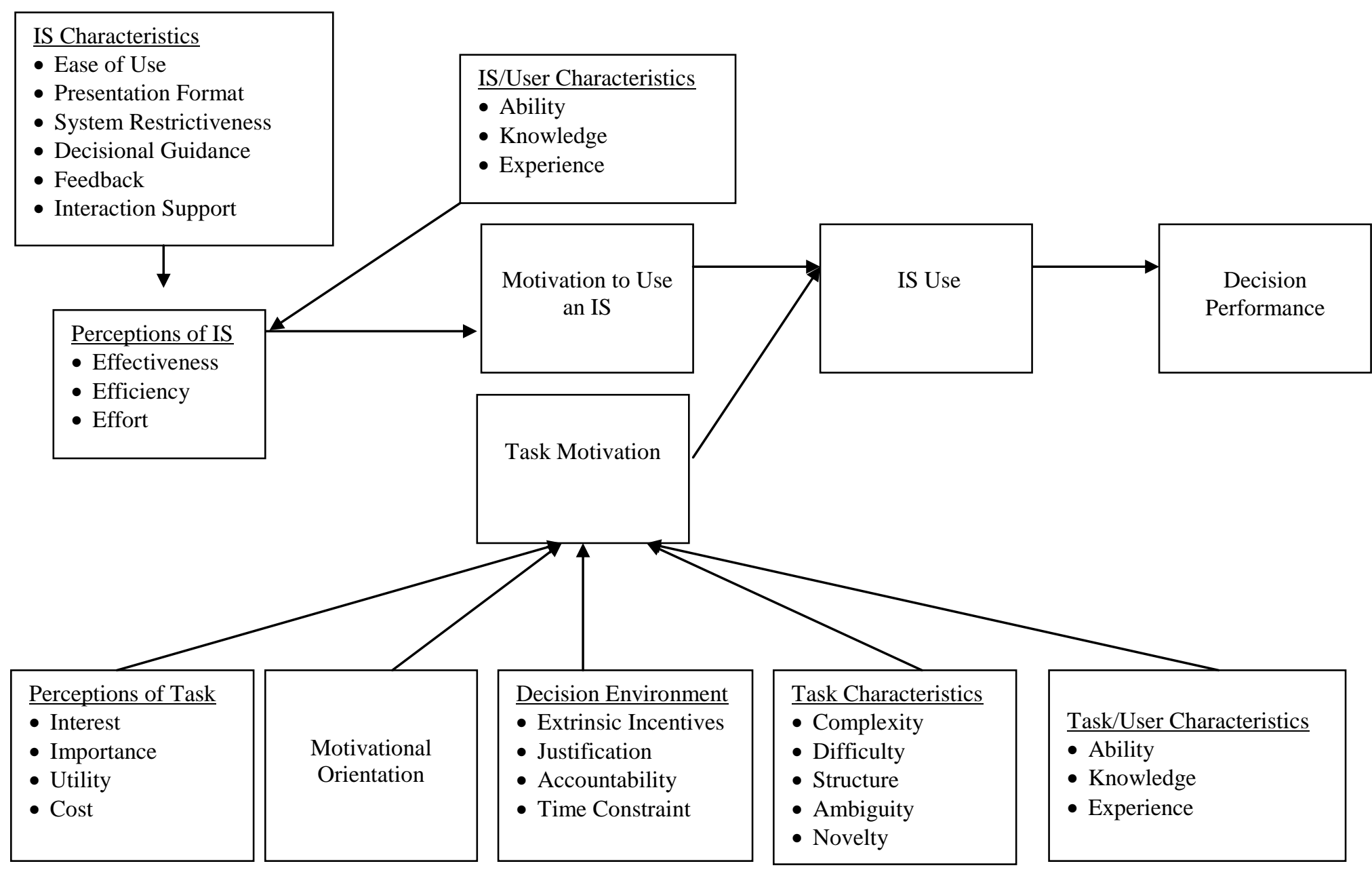




\section{NOTES}

